\title{
POLLINATION ANALOGIES BETWEEN ORCHIDACEAE, FICUS (MORACEAE) AND ASCLEPIADACEAE
}

\author{
WILLIAM RAMÍREZ-B. \\ Emeritus Professor, Universidad de Costa Rica, Facultad de Ciencias Agroalimentaria \\ clizano@yahoo.com
}

\begin{abstract}
Resumen. Las orquídeas, así como Asclepiadaceae, poseen polinios para transportar polen masivamente. Algunos de los géneros de avispas (Agaonidae), que polinizan a los higos (Moraceae: Ficus), poseen cavidades (sacos torácicos y corbículas coxales) donde el polen se transporta. Estos dispositivos en sendos grupos, probablemente evolucionaron para facilitar el transporte de abundantes granos de polen, por largo tiempo y distancia, sin que éste se deshidrate o se desprenda de los insectos vectores. Estas estructuras condujeron a la evolución de granos de polen pequeños, livianos, semihemisféricos, parcialmente deshidratados, sin ornamentaciones, colores y olores atractivos. La evolución de estos dispositivos condujo a la evolución de polinizadores específicos, a la especiación isopátrica, endemismo y producción de síndromes de polinización análogos. Se postula que los estigmas de Ficus no son receptivos y son secos; consecuentemente, los estigmas de las flores "agalla" y flores "semilla" se tornan húmedos y receptivos cuando son "picados" por el ovipositor de las avispas. Las estructuras para transportar polen en las avispas de los higos han evolucionado varias veces; y es posible que lo mismo aconteció con la evolución de polinios en las orquídeas. La evolución de estas estructuras en los organismos mencionados, puede haber sucedido durante períodos geológicos de sequía.
\end{abstract}

KEY WoRDS: pollen, containers,fig,wasps, Agaonidae, Asclepiadaceae

\section{Introduction}

In the majority of animal-pollinated angiosperms, as well as insect-pollinated gymnosperms (e.g. cycads) the acquisition of pollen by the animal vector is incidental or at least not deliberate. The pollinators usually become dusted with non-coherent pollen when they contact the anthers. The loose powdery pollen is made up by monads, which are large, with well developed and heavily sculptured exine-intine. Pollen adheres to the vectors by different physical mechanisms. The pollen carrying vectors visit other flowers usually of the same plant species, and accomplish incidental pollination. The time lapse from pollen acquisition to the act of pollination usually takes a short time. Moreover, pollen is carried in the general body surface of the vectors, where it is subject to be scraped, rubbed, blown away or washed off by rain. Consequently, transport of loose pollen grains to a long distance is practically impossible. Moreover, the exposed pollen suffers dehydration (Ramírez-B. 1989; Pacini \& Hesse 2002).
Dehydration of pollen during transport, as well as pollen hydration during deposition on the stigmas and germination, are critical phases. These problems are more important, especially when the vectors, as well as the stigmas are exposed to solar radiation, air currents (Pacini \& Hesse 2002), or when the stigmas are dry, as probably occurs in Ficus. The "advanced" orchids have evolved different kinds of pollinia which act as pollen transportation containers, while some "advanced" genera of fig-wasp pollinators have evolved hidden body containers (pollen pockets and corbiculae) to transport pollen to be used in future pollination (Ramírez-B 1969; Ramírez-B \& Malavasi 1997). The Asclepiadaceae have also pollinia, and are the dicot counterpart of the "advanced" Orchidaceae (Wyatt \& Broyles 1994). Pacini \& Hesse (2002) noted that "pollen longevity should be considered in relation to whether it is inside or outside the anther." While Jersáková et al. (2005) noted that "among animal-pollinated species, the fate of the transported pollen depends fundamentally on whether pollen travels as independent grains or aggregations." 
Ramírez-B. (1989) postulated that the evolution of the adult shortly-lived symbiotic agaonid pollinators of Ficus probably saves the pollen from desiccation and death. He noted that Ficus species have not evolved genetic mechanisms of isolation and that isopatric speciation may have also occurred. The remarkable closed pollinating mechanisms in Ficus and in the orchids may have had a causal relationship to their extensive speciation and endemism (RamírezB. 1970a; 1986)

The objective of this work was to explain why the "advanced" orchids (as well as Asclepiadaceae) have evolved pollen containers (e.g. pollinia) and why some "advanced" pollinator genera of Ficus have also evolved containers to carry pollen. Compare the pollination syndrome analogies between the orchids (Orchidaceae), of Ficus (Moraceae), and Asclepiadaceae, as well as, to discuss their implications in the evolutionary consequences in those groups.

Ficus (Moraceae). Ficus is characterized by the urceolate closed inflorescence (the syconium), and its dependence on insect pollination. It is one of the largest genera of tropical woody plants with $c a .750$ spp. (Berg 1990). In the Urticales successful adaptation to insect pollination is only known for Ficus, with the pseudocarpous inflorescences (Berg 1977). Pollen or other floral rewards in Ficus are unknown.

The symbiotic pollinators of Ficus belong to Agaonidae (Hymenoptera: Chalcidoidea). At oviposition , the agaonid wasps rupture ("sting") the stigmas of all fig florets and introduce the ovipositor along the style and deposit one egg inside the fig ovary of some of them. The female wasps are usually not hairy and scarcely any pollen is found on the external surface of their bodies when they penetrate the receptive syconia (Galil \& Eisikowitch 1969). Each fig species produces specific attractants when the syconia are receptive (van Noort \& Compton 1996 and references therein). The inflorescences have hundreds or thousands (Condit 1920) of small uniovulate florets. Fig pollen grains are very small (Cunningham 1889) pure white (Cunningham, 1889, Condit 1920, Pemberton 1921), smooth (Verkerke 1986), spherical or slightly oval (Condit 1920).

"Primitive" Ficus species (e.g. F. carica L.) have many long pedicellate male flowers, with multiple large introrse anthers, up to six (Condit, 1920), with slender filaments (Berg 1990). They also have a well developed endothecium that allows wide opening of the anthers and explosive discharge of pollen (Galil \& Neeman 1977); thus, pollen does not come out naturally from the anthers (Ramírez-B. 1970b, 1974; Galil $\&$ Meiri 1981). The enclosed new generation of wasps becomes completely dusted with pollen grains (monads) (Eisen 1896; Pemberton 1921, Ramírez-B. 1974; Galil \& Meiri 1981) which are later used for pollination of the female florets of the receptive syconia of another fig tree. In the "primitive" figs, pollination is accidental and the wasps accomplish passive pollination. On the contrary, the "advanced" species of figs usually have simple stigmas, few short-pedicellate or sessile male flowers with few "small" anthers (-3) with short filaments. The endothecium is degenerate and does not actively open the anther (Galil \& Eisikowitch 1968; Galil 1984); consequently, the emerging adult female wasps have to extract the pollen from the anthers by using the arolia of the fore legs and introduce it into special hidden cavities or containers, pollen pockets (Figs. 5,6,7) and corbiculae (Ramírez-B. 1969, 1970a). At oviposition, the wasps simultaneously extract pollen from the containers by means of the arolia of the fore legs. Then, the pollen grains are shaken or rubbed on the stigmas or synstigmas. In fig species with symbiotic wasps that posses pollen containers, pollination is "deliberate" and they accomplish active pollination. Galil \& Eisikowitch (1971) questioned for the first time," what could have been the selective advantage that promoted the development in (the fig wasps) of unique pollen pockets and the appropriate instincts to load these pockets in old figs and empty them in receptive figs during the oviposition act?"

The female florets of Ficus seem to have nonreceptive dry stigmas. It is known that in the "female flowers" of Ficus. carica L. (the edible fig), and probably other species, the stigmas are covered with multiple minute glands, which become greatly swollen and somewhat glossy of a green light color (Eisen 1896). Verkerke $(1986,1987)$ also noted that the stigmas of the "female" and "gall flowers" of $F$. asperiifolia Miq. and F. ottonifolia (Miq.) Miq. (species which have active pollination), become 


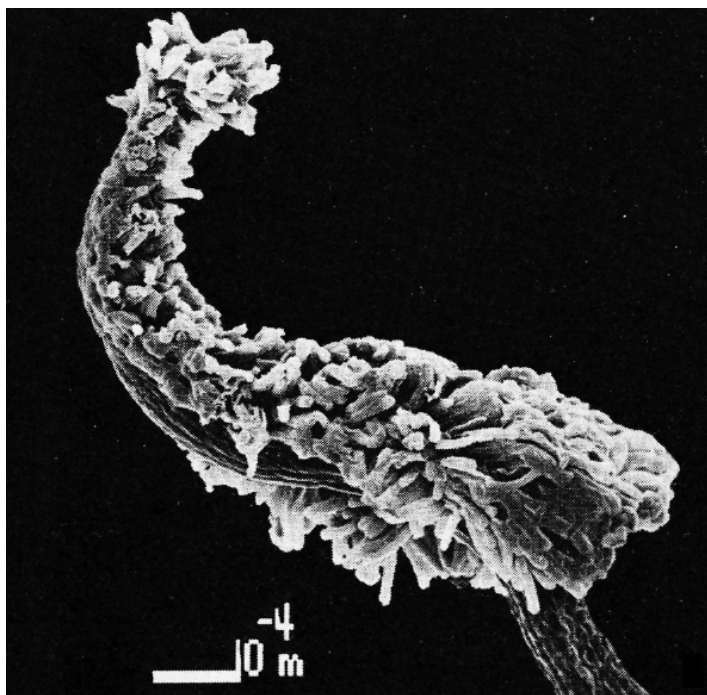

FIGURE 1. F. ottonifolia. Seed flower at pre-fertilization time (after Verkerke, 1986; Fig. 5d).

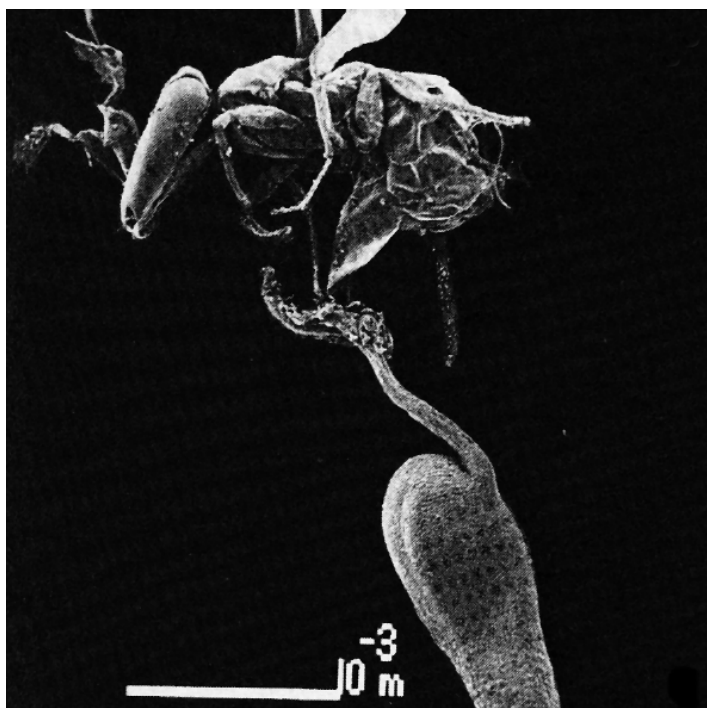

Figure 3. F. ottonifolia. Gall flower penetrated by the ovipositor of Courtella gabonensis Wiebes (after Verkerke, 1986; Fig. 6b).

shortly papillate when receptive as in (Figs. 1,2).

The supposed dry non-receptive stigmas of Ficus probably do not posses a natural sugar-rich solution or "stigmatic fluid" for pollen hydration and germination. This has been indirectly demonstrated by the successful manual pollination and the production of viable seeds when pollen-sugar solutions were introduced into the receptive syconia, of different fig species (Condit 1950; Neeman \& Galil 1978;

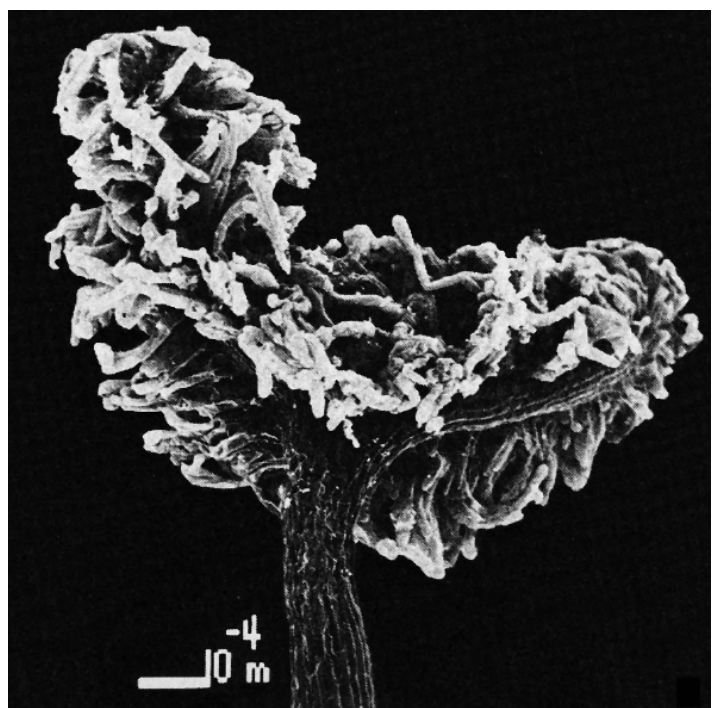

FIGURE 2. Ficus ottonifolia (Miq.) Miq. Gall flower at prefertilization time (after Verkerke, 1986; Fig. 4d).

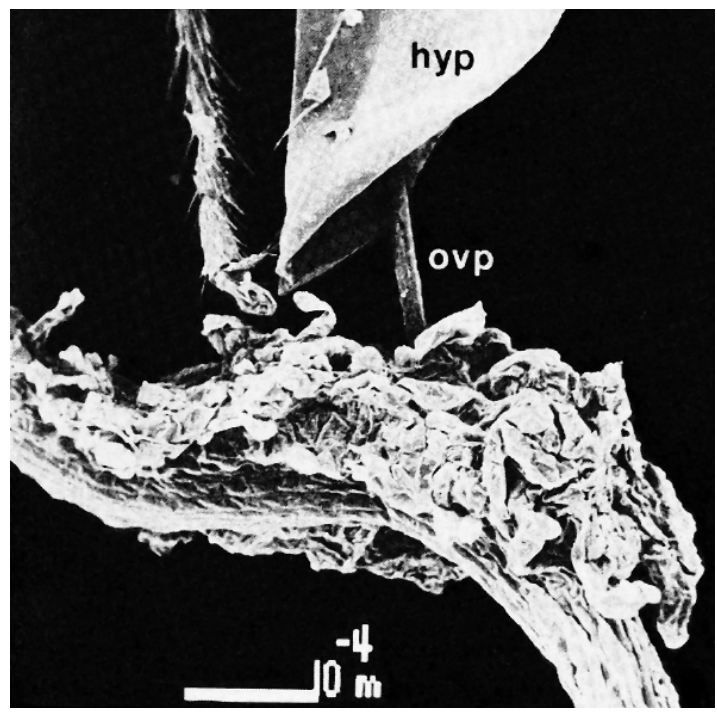

Figure 4. F. ottonifolia. Gall flower penetrated by the ovipositor of Courtella gabonensis (after Verkerke, 1986; Fig. 6c): hyp=hypopygium, ovp=ovipositor.

Ramírez-B. 1986). Since the fig stigmas or synstigmas are probably dry, each stigma and style have to be ruptured or "stung" by the wasps' ovipositors (Fig. $3,4)$ in order to secrete a stigmatic fluid that allows pollen hydration, vacuolation, and germination; as well as pollen tube penetration and fertilization. Galil \& Eisikowitch (1969) also report that the female Ceratosolen arabicus Mayr not only "sting" the styles but also gnaws the stigmata during oviposition. 
ORChIDACEAE. The Orchidaceae constitute one of the largest group of monocots, estimates range from 17-35 000 species (Dressler 1993). The "advanced" orchids have quite specific insect pollinators (Dressler 1968). According to Nepi et al. (2001) pollen reward is unknown in the orchid flowers, except in Neuwiedia veratifolia B1.. Yeung (1987) noted that "the most notable feature in orchid pollen development is that the different pollen grouping can be found".

The "primitive" orchids had introrse anthers as in Ficus. Nevertheless, in Cleistes divaricata (L.) Ames, a hinged anther dispenses a sequence of loosely aggregated pollen tetrad masses... (Gregg 1991). In the "primitive" Apostasioideae, pollen is produced in loose monads (Singer et al., 2006). In Neuwiedia spp. it is powdery and not coherent (Dressler 1993). The pollen has well developed exine and intine. In N. veratifolia Blume (Apostasioideae) the anthers are tubular as in buzz flowers (Dressler, $\mathrm{R}$, pers. comm. 2007). Pollen, as in most angiosperms is accidentally loaded and transported on the body of the pollinator agents (bees and other vectors). The stigmas of orchids with monads and tetrad pollen, is more or less humid as that of other angiosperms (Pacini \& Hesse, 2002). In Apostasioideae pollination must be accidental.

In the more "advanced" orchids pollen grains are agglutinated in different ways, e.g. in Phragmipedium (Cypripedoideae) are monads, sticky and pastelike or united into pollinia (Dressler 1993); in other Orchidaceae pollen is agglutinated in soft or divisible pollinia and in the Epidendroideae indivisible pollinia (Singer et al. 2006). Pacini \& Hesse (2002) noted that "(orchid) pollen longevity should be considered in relation to whether pollen is exposed or protected", and that "different kinds of pollinia are found exclusively in Orchidaceae" (Pacini \& Hess 2002 and reference therein).

Massulate orchids have little or no locular fluid and pollen hydration, unlike other angiosperms, and rehydration occurs inside the closed cavity of the stigma (Pacini \& Hess 2002 and reference therein). The smaller size in orchid pollen is due to the lack of the vacuolated stage that is so common in angiosperm pollen (Pacini \& Hesse 2002). They also noted that "if pollen increased as much as much of that of other angiosperms, it would be impossible to have a compact pollinium."
Asclepiadaceae. The Asclepiadaceae are the dicot counterpart of the Orchidaceae, which also transmit the pollen in large groups within pollinia (Wyatt \& Broyles 1994). They produce capsules with hundreds of seeds. Milkweed flowers are long-lived and produce copious nectar which flows from nectaries within the stigmatic chamber. Nectar also serves as the germination fluid for pollen grains (Wyatt \& Broyles 1994). Most milkweeds species are genetically incompatible (Wyatt \& Broyles 1994), and they seem to depend on quite specific pollinators.

\section{Discussion}

In most of the animal-pollinated angiosperms, as well as those insect pollinated gymnosperms (e.g. cycads), the mature anthers, split open longitudinally to release the pollen (Yeung 1987) and the acquisition of pollen by the animal vectors is accidental. The loose ornamented and reticulated pollen grains have well developed exine and intine and become adhered to the vector by different physical mechanisms. The pollen-carrying vector visit other conspecific flowers, and accidentally rubs the pollen in the stigmas; thus, pollen usually remains on the vector for quite short time. Since pollen is carried on the general vectors' body surfaces, it is subject to be scraped, rubbed, blown; or washed off, as well as to dehydration and death; consequently, the transport of pollen in heavy masses or simple units (monads) for a long time and distance is practically impossible.

Pollen dehydration during the transport, as well as, pollen hydration, pollen tube emergence and penetration through the stigmatic styles are critical phases. This is especially important when the stigmas are exposed to solar radiation and air currents or when they do not possess stigmatic fluid. In the genus Ficus the pollinators of the more "primitive" genera, most of the powdery pollen is transported as monads on the general surface of the pollinator, or between the intersegmental folds (Galil \& Neeman 1977).

However, the pollinators of several "advanced" Old World fig genera have evolved discrete pollen containers, pockets (Figs. 5-7) and corbiculae (Ramírez-B. 1969, 1997). These structures are deliberately loaded at pollen acquisition and unloaded during pollination. In those containers the fig-wasps may 

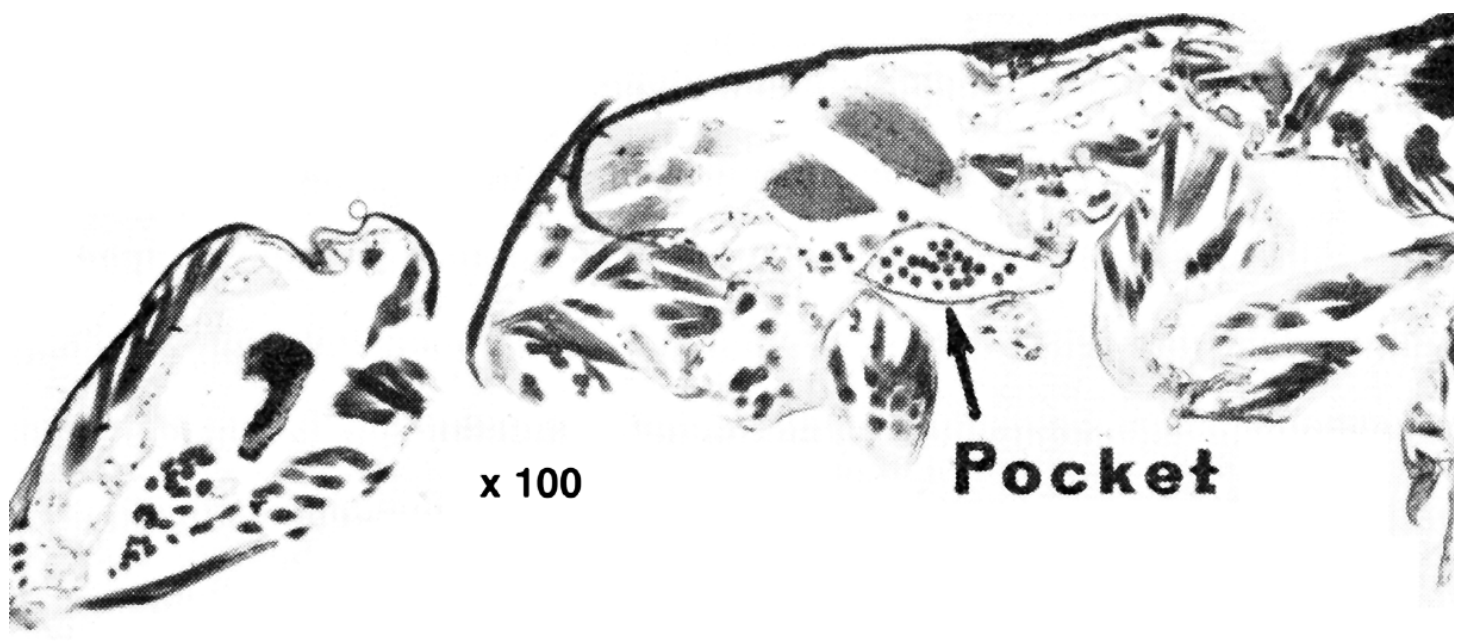

FIGURE 5. Blastophaga quadraticeps L., the pollinator of Ficus religiosa L. Longitudinal section of female showing pollen pockets (after Galil and Eisikowitch, 1970; Fig. 9).

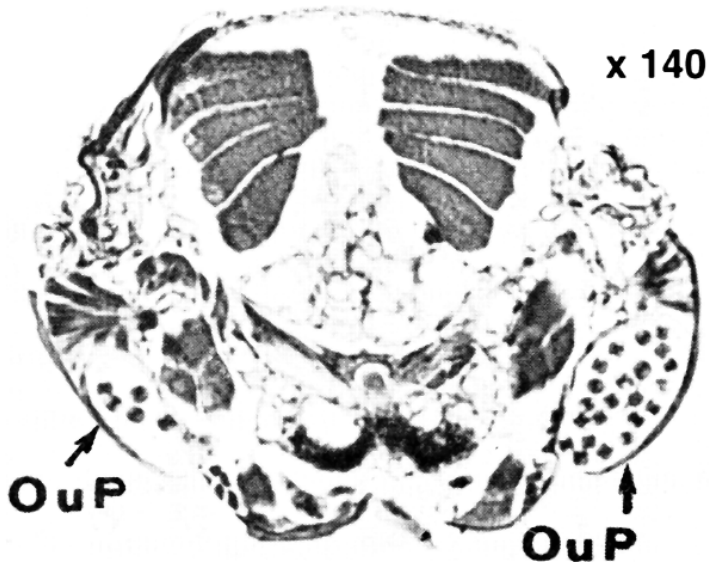

FiguRE 6. B. quadraticeps. Transverse section of mesothorax showing pollen pockets (after Galil and Eisikowitch, 1970; Fig. 11): Oup=outer plate.

carry hundreds or thousands of pollen grains (Fig. 7). Ramírez-B. (1989) postulated that the evolution of short-lived fig pollinator, as well as of discrete pollen transporting containers in some of the fig wasps was a mechanism to protect the pollen grains from desiccation, since there is a lapse of hours or days between pollen acquisition and pollination. This lapse of time between pollen acquisition and pollination is also a common fact in "advanced" orchids. In the "primitive" orchid (e.g. Apostasioideae) the loose pollen, as in the "primitive" figs, is probably transported on the

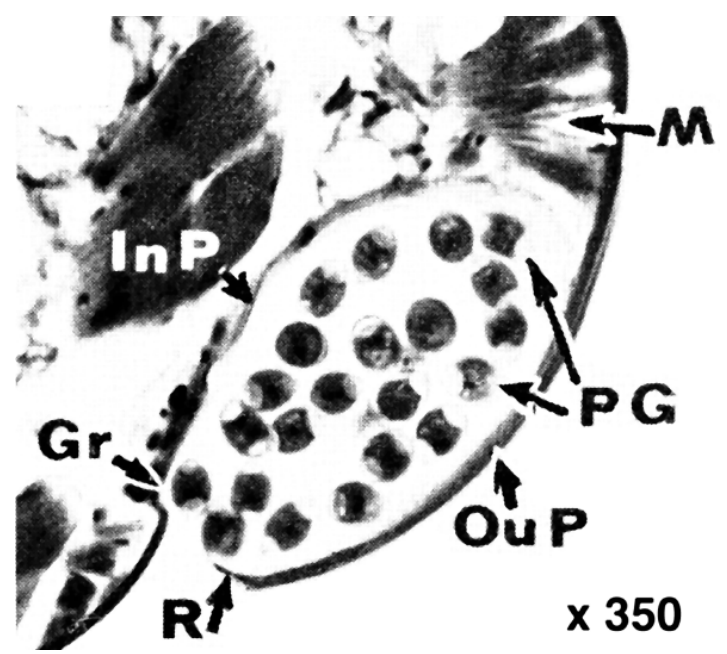

Figure 7. B. quadraticeps. Transverse section of pollen pocket (after Galil and Eisikowitch, 1970; Fig. 10): $\mathrm{M}=$ muscle, $\mathrm{PG}=$ pollen grains, Oup = outer plate, $\mathrm{R}=$ rim, $\mathrm{Gr}=$ groove, $\mathrm{InP}=$ inner plate.

general body of the pollinating insects (probably bees).

The "advanced" orchids, as well as the species of Ficus are associated with very specific insect pollinators that isolate and prevent hybridization between compatible populations. This close association has led to fast speciation without geographical isolation (Ramírez-B. 1970a) and to endemism. Since fig species as well as the "advanced" orchid (and probably Asclepiadaceae) species are pollinated by quite constant pollinators they do not seem to have evolved genetic 
TABLE 1: Common analogies in Orchidaceae and Ficus (Moraceae).

Disruption in the production of pollen monads.

Flower anthesis last from few hours to several weeks (Endress 1994).

Elimination of bright attractive pollen colors.

Reduction of exine, intine layers and pollen ornamentation.

Elimination of pollen reticulations.

Production of small uniform semispherical light pollen grains.

Partial or total elimination of locular fluid.

Production of partially or totally dehydrated pollen grains, or lack of the vacuolated stage.

Reduction of the number of male flowers and anthers per male flower.

Synchronous development, production and maturation of pollen, and extension of flower anthesis (Endress 1994).

Prevention of pollen dehydration and death (Ramírez-B. 1989).

Vacuolization of pollen on the stigmas (Pacini \& Hess 2002).

The pollinators carry more pollen grains per load and for longer periods.

Elimination of mechanical or liquid attachments (Pacini \& Hesse 2004).

Prevention of pollen grains from being blown away, scrapped, rubbed or washed off during transport to the stigma.

Prevention of pollen waste.

Pollen may survive for longer times before pollination and pollen germination (Nepi et al. 2001)

Production of long-lived flowers, especially in orchids.

Evolution of very specific pollinator adapted to the flowers morphology in orchids or to the inflorescences physiology and morphology in Ficus.

Evolution of sympatric speciation and endemisms.

Reduction or elimination of anthers' locular fluids.

Reduction or fusion of floral parts.

The evolution of specific floral attractants and morphologies that fitted the behavior, morphology and size of the pollinator.

Evolution of bizarre and colorful flowers in the orchids and of intricate ostiolar entrances in Ficus.

Increased number of ovules per capsule (Pacini \& Hesse, 2002) in the orchids; as well as the number of female flowers per syconium of Ficus species.

Reduction of geitonogamous pollination (Johnson \& Edward 2000).

Production of stigmatic complexes in the orchids and Asclepiadaceae and of synstigmas in Ficus.

Increase of cross pollination (Jersáková et al. 2006).

Synchronous fertilization of hundreds, thousands or millions of orchid ovules, or of hundreds or thousands of female fig florets in a single pollination act.

Inhibition of promiscuous pollination.

Production of seeds from a single father (Wyatt \& Broyles 1994)

Production of very small seeds.

Evolution of symbiotic germination and epiphytism.

mechanisms of isolation. Instead of, Ficus and the "advanced" orchids evolved physiological, mechanical, ecological, an ethological mechanisms of isolation.
The evolution of discrete pollen-carrying containers (pollinia) in the orchids and in some of symbiotic pollinators of Ficus (pollen pockets and corbiculae) 
has had an evolutionary impact in the phylogeny of both groups; as well as in their insect pollinators. It led to the production of multiovulate orchid ovary and to fig inflorescences with hundreds or thousands of ovules or female florets and few male flowers. The fig syconium is analogous to the multiovulate orchid and Asclepias ovaries, and the ripe inflorescence to the orchid or Asclepias capsules.

It is probable that the orchid pollinia may have evolved several times, while in the pollinators of Ficus, they seem to have evolved independent in at least in six lines of wasps, as a case of convergence (Ramírez-B. 1978). However, according to Machado et al. 2001, those structures evolved only once and had been lost in several agaonid wasps due to reversals. The evolution of pollen transporting devices, both in plants and animals, may have occurred during geological climatic dry spells.

The evolution of pollen containers in some of the orchids and in some symbiotic fig wasps have also contributed to he appearance of analogous syndromes (Table 1), which probably also occurs in the Asclepiadaceace. The evolutionary pattern in the "advanced" orchids, as well as in Ficus, has probably being influenced by their unique pollinating mechanisms. Since the female florets of Ficus seem to have dry stigmas, it is postulated that the stigmas must be ruptured ("stung") by the pollinating wasp's ovipositor, or that biting of the stigmas induce the production of the stigmatic liquid that allows pollen germination.

ACKNOWLEDGMENTS. The author is indebted to Robert $\mathrm{L}$. Dressler, for the useful comments on the manuscript; the staff of the Lankester Botanical Garden, and to the Organization for Tropical Studies Library (OTS) for providing literature. To Gilbert Fuentes for his comments and typing of the manuscript.

\section{LITERATURE CITED}

Berg, C.C. 1950. An interspecific hybrid in Ficus. J. Hered. 41: 165-68.

Cunningham, D.D. 1889. On the phenomena of fertilization in Ficus roxburghii, Wall. Ann. Roy. Bot. Gard. Calcutta 1: 13-51.

Berg, C.C. 1977. Urticales, their differentiation and systematic position. Plant Sys. Evol. Suppl. 1: 349-74.

Berg, C.C. 1984. Floral differentiation and dioecism in Ficus (Moraceae). Mini Symposium Figs and Fig
Insects, p. 15-25. Montpellier Cédex: Centre National de la Recherche Scientifique.

Berg, C.C. 1990. Reproduction and evolution in Ficus (Moraceae): traits connected with the adequate rearing of pollinators. Mem. New York Bot. Gard. 55: 169-85. Condit, I.J. 1920. Caprifigs and caprification. Univ. Calif. Exp. Sta. Bull. 319: 341-75.

Dressler, R. L. 1968. Pollination by euglossine bees. Evol. 22(1): 202-10.

Dressler, R. L. 1993. Phylogeny and classification of the orchid family. 314 pp. Portland: Dioscorides Press.

Eisen, G. 1896. Biological studies on figs, caprifigs and caprification. Calif. Acad. Sci. (Second Series) 5: 8971003.

Endress, P.K. 1994. Diversity and evolutionary biology of tropical flowers. 500 p. Cambridge: Cambridge University Press.

Galil, J. 1973. Pollination in dioecious figs: pollination of Ficus fistulosa by Ceratosolen hewitti. Gardens' Bulletin 26(2): 303-11.

Galil, J. 1984. Anther dehiscence in fig syconia. Mini Symposium Figs and Fig Insects, p. 35-40. Montpellier Cédex: Centre National de la Recherche Scientifique.

Galil, J. \& D. Eisikowitch. 1969. Further studies on the pollination ecology of Ficus sycomorus L. Tijdschr. Entomol. 112: 1-13.

Galil,Y. \& Snitz-Pasternak. 1970. Pollination in Ficus religiosa $\mathrm{L}$. As connected with the structure and mode of action of the pollen pockets of Blastophaga quadraticeps Mayr. New Phytol. 69: 775-784.

Galil, J. \& D. Eisikowitch. 1971. Studies on mutualistic symbiosis between syconia and sycophilous wasps in monoecious figs. New Phytol. 70: 773-87.

Galil, J. \& L. Meiri. 1981. Number and structure of anthers in fig syconia in relation to behaviour of the pollen vectors. New Phytol. 88: 83-87.

Galil, J. \& G. Neeman. 1977. Pollen transfer and pollination in the common fig (Ficus carica L.). New Phytol. 79: 163-171.

Greeg, K.R. 1991. Reproductive strategy of Cleistes divaricata (Orchidaceae). Am. J. Bot. 78: 350-360.

Jersáková, J., S.D. Johnson \& P. Kindlmann. 2006. Mechanisms and evolution of deceptive pollination in orchids. Biol. Rev. 81: 1-17.

Johnson, S.D. \& T.J. Edwards. 2000. The structure and function of orchid pollinaria. Plant Syst. Evol. 203: 9198.

Machado, C.A., M. Jousselin, F. Khellberg, S.G. Compton \& E.A. Herre. 2001. Phylogenetic relationship, historical biogeography and character evolution of fig-pollinating wasps. Proc. Roy. Soc. London - Biol. Sci. 268: 685-694.

Neeman, G. \& J. Galil. 1978. Seed set in the 'male syco- 
nia' of the common fig Ficus carica L. (Caprificus). New Phytol. 81: 375-80.

Nepi, M. G.G. Franchi \& E.P. 2001. Pollen hydration status and dispersal: cytophysiological features and strategies. Protoplasma 216: 171-180

Noort van, S. \& S.G. Compton. 1996. Convergent evolution of Agaonine and sycoecine (Agaonidae, Chalcidoidea) head shape in response to the constraints of host fig morphology. J. Biogeogr. 23: 415-24.

Pacini, E. \& M. Hesse. 2002. Types of pollen dispersal units in orchids, and their consequences for germination and fertilization. Ann. Bot. 89: 653-64.

Pemberton, C.E. 1921. The fig wasp in its relation to the development of fertile seed in the Moreton Bay fig. Hawaiian Plant. Rec. 24: 297-319.

Pridgeon, A. M., P.J. Cribb, W.W. Chase \& F.N. Rasmussen. 1999. Apostasioideae. Pp. 94-96 . in: A. M. Pridgeon, P. J. Cribb, W. W. Chase \& F. N. Rasmussen (eds.). Genera Orchidacearum. Vol. 1. Oxford, Oxford University Press.

Ramírez-B., W. 1969. Fig wasps: mechanism of pollen transfer. Science 163: 580-81.

Ramírez-B., W. 1970a. Host specificity of fig wasps (Agaonidae). Evolution 24(4): 680-691.

Ramírez-B., W. 1970b. Taxonomic and biological studies of neotropical fig wasps. Univ. Kans. Sci. Bull. 49, no. 1: $1-44$.

Ramírez-B., W. 1974. Coevolution of Ficus and Agaonidae. Ann. Missouri Bot. Gard. 61: 770-780.

Ramírez-B., W. 1978. Evolution of mechanisms to carry pollen in Agaonidae (Hymenoptera: Chalcidoidea).
Tijdschr. Entomol. 121(6): 279-93.

Ramírez-B., W. 1986. Artificial hybridization and self-fertilization in Ficus (Moraceae). Brenesia 25/26: 265-72.

Ramírez-B., W. 1989. Dispersal and colonization of Ficus in the New World. Pp. 279-84 in: P.R. Crane \& S. Blackmore (eds.). Evolution, Systematics, and Fossil History of the Hamamelidae, vol. 2: 'Higher' Hamamelidae. Oxford: Clarendon Press.

Ramírez-B., W. \& J. Malavasi. 1997. Fig wasps: mechanisms of pollen transfer in Malvanthera and Pharmacosycea figs (Moraceae). Rev. Biol. Trop. 45(4): 1635-40.

Singer, R.B., A.J. Marsaioli, A. Flach \& M.G. Reis. 2006. The ecology and chemistry of pollination in Brazilian orchids: recent advances. Vol. 1. Pp. 569-82 in: J.A. Teixeira da Silva (ed.). Floriculture, Ornamental and Plant Biotechnology: Advances and Topical Issues. Londron, Global Science Books.

Verkerke, W. 1986. Anatomy of Ficus ottoniifolia (Moraceae) syconia and its role in the fig-fig wasp symbiosis. Proc. K. Ned. Akad. Wetensc. 89(4): 443-69.

Verkerke, W. 1987. Syconial anatomy of Ficus asperiifolia (Moraceae) a gynodioceious tropical fig. Proc. K. Ned. Akad. Wetensc. 90(4): 461-92.

Wyatt, R., \& S.B. Broyles. 1994. Ecology and evolution of reproduction in milkweeds. Annu. Rev. Ecol. Sys. 25: 423-41.

Yeung, E.C. 1987. Development of pollen and accessory structures in orchids. Pp. 193-226 in: J. Arditti (ed.). Orchid Biology: Reviews and Perspectives. Vol. IV. Ithaca, New York, Cornell University Press. 